\title{
Management Dilemmas in Threatened Preterm Labor (TPTL) and its Impact: A Mini Review
}

\author{
Meenoo $\mathrm{S}^{1^{*}}$, Bhoomika Tantuway ${ }^{2}$, Karishma Bhatia ${ }^{3}$ \\ ${ }^{1}$ Department of Obstetrics and Gynecology, Maulana Azad Medical College, New Delhi, India; ${ }^{2}$ Department of Obste trics and \\ Gynecology, NSCB Medical College, Jabalpur, Madhya Pradesh, India; ${ }^{3}$ Department of Obstetrics and Gynecology, Max Hospital, \\ NewDelhi, India
}

\begin{abstract}
Prematurity is a primary cause of neonatal mortality worldwide. The survivors also suffer long term complications and significant permanent neurodevelopmental disability. It contributes to about $70 \%$ of neonatal deaths and $36 \%$ of infant mortality. Neonatal mortality can be reduced by appropriate diagnosis, administration of corticosteroids, judiciary use of tocolytics and timely transfer to a centre with neonatal intensive care unit. Only about 10\%-30\% of cases with symptoms of preterm labor proceed to preterm delivery. Hence, it is necessary to differentiate between true preterm labor and threatened preterm labor (TPTL). The latter is diagnosed with onset of regular uterine contractions (at least one in ten minutes) with minimal or no cervical changes and intact membranes. There is no exact definition of TPTL and it varies between various institutions and countries. Over the last decade, there has been a tremendous development to aid in the prediction of preterm labor. Recently, transvaginal cervical length measurement and presence of fetal fibronectin (ffn) and/or phosphorylated insulin growth factor binding protein - 1 (phIGFBP - 1) in cervical fluid can be used to delineate between true and threatened preterm labor.
\end{abstract}

Keywords: Prematurity; Dilemmas; Threatened preterm labor (TPTL); Fetal fibronectin test

\section{MINI REVIEW}

ACOG recommends the use of fetal fibronectin test and cervical length measurement alone or in combination to diagnose preterm birth [1]. However, in cases with acute symptoms, since the positive predictive value of positive ffn test or short cervix is poor, they should not be used to decide further management. Transvaginal cervical length measurement was widely studied by various authors to predict preterm labor and had been found to have high negative predictive values ranging from 94.9 to $97.1 \%$ depending on the threshold used [2-4]. However, Cochrane review on knowledge of cervical length for prediction of preterm labor did not have significant difference in reduction of preterm birth and the results were inconclusive [5].

Many observational studies proved that use of ffn test in prediction of preterm birth made significant cost reduction in hospital expenses [6,7]. In contradictory to this, a systematic review and meta-analysis showed that fetal fibronectin testing in assessing preterm labor was not associated with prevention of preterm birth or improvement in perinatal outcome instead caused higher costs [8]. A study conducted in Netherlands which compared the use of ffn test and cervical length alone and in combination for cost effectiveness showed that maximum cost reduction was found in the category where additional $\mathrm{ffn}$ testing was done in patients with cervical length of $15-30 \mathrm{~mm}$ [9]. Cochrane review done on assessment of effectiveness of management based on the knowledge of fetal fibronectin (ffn) test results in preventing preterm birth showed that knowing the ffn test result reduced preterm birth rate before 37 weeks. However, there was no significant difference in delivery less than 34 weeks or 32 weeks [10]. The main drawback in this review which included six trials was that all the evidences were of low quality and cost effectiveness analyses were not available. Despite, many research studies in the last two decades, the use of $\mathrm{ffn}$ test in reducing hospital expenses remains controversial.

Correspondence to: Meenoo S, Department of Obstetrics and Gynecology, Maulana Azad Medical College, New Delhi, India, Tel: 918376885020; E-mail: meenoosubbu@gmail.com

Received: December 23, 2019; Accepted: January 09, 2020; Published: January 16, 2020

Citation: Meenoo S, Tantuway B, Bhatia K (2020) Management Dilemmas in Threatened Preterm Labor (TPTL) and its Impact: A Mini Review. Clinics Mother Child Health. 17:340. DOI: 10.35248/2090-7214.20.17.340.

Copyright: ( $) 2020$ Meenoo S, et al. This is an open-access article distributed under the terms of the Creative Commons Attribution License, which permits unrestricted use, distribution, and reproduction in any medium, provided the original author and source are credited. 
Another biochemical marker, that was widely studied, was phosphorylated insulin growth factor binding protein - 1 which also had a very high negative predictive value in predicting preterm birth. This was also found to reduce unnecessary admissions and expenses if it was used for triaging women with symptoms of threatened preterm labor [11]. The advantage of phIGFBP-1 over $\mathrm{ffn}$ is that it is not detected in urine or seminal fluid. Therefore, it can be used to diagnose threatened preterm labor even if the patient had a sexual intercourse in the past 24 hours where ffn may show false positive results. Henceforth, large trials or randomized controlled study are recommended to prove the cost effectiveness of this test so that it can be implemented in the future protocols.

Recently, many novel biochemical markers were used to predict delivery in threatened preterm labor. One among them was placental alpha macroglobulin-1 in cervicovaginal secretions and was used to triage threatened preterm labor. It showed high specificity (97\%-98\%) and high negative predictive value (89\%-97\%) in predicting delivery within 2 days, 7 days and 14 days [12]. This marker when combined with cervical length measurement also showed high positive predictive value (100\%). Another study done in Turkey showed that maternal serum endocan levels were higher in patients with true preterm labor $(823 \mathrm{pg} / \mathrm{mL})$ and high in patients with false preterm labor (637 $\mathrm{pg} / \mathrm{mL}$ ) when compared to uncomplicated pregnancies (310 pg/ $\mathrm{mL}$ ). The importance of this marker was it was raised even when there was no significant difference in cervical length between patients who delivered term and preterm [13].

The most important aspect after diagnosing preterm labor is commencing tocolysis with appropriate drug so that administration of steroids and transfer to centre with NICU facility can be done accordingly. Use of tocolytics in threatened preterm labor is yet to be studied clearly. A study conducted in Pakistan [14] showed that after successful inhibition of contraction with nifedipine, additional maintenance therapy with vaginal progesterone $200 \mathrm{mg}$ daily resulted in significant prolongation of pregnancy when compared to patients who did not use vaginal progesterone. $(29.73 \pm 3.10$ days vs. $11.13 \pm 5.08$ days). A study conducted in southern part of India to assess the efficacy of Isoxsuprine hydrochloride in threatened preterm labor showed $100 \%$ success rate and an apparent lengthening of pregnancy [15]. The main limitation of this study was its sample size $(n=50)$ and it was a non-comparative study. A randomized double blinded study conducted in Thailand showed that use of nifedipine (after three loading doses) showed a higher success rate in inhibiting contractions after 90 minutes of initiation of treatment compared to placebo ( $88.3 \%$ vs. $69.9 \%)$.

The success rate after $48 \mathrm{~h}$ of initiation of treatment was $77.6 \%$ in the former group vs. $49.5 \%$ in the latter [2]. Hence, bed rest, adequate hydration and close observation for 60 to 90 minutes can be considered as the first line treatment for patients presenting with threatened preterm contractions as $69.9 \%$ patients underwent spontaneous resolution of contractions within 90 minutes. In this way, unnecessary use of tocolytics could be avoided. Likewise, ACOG recommends avoiding use of tocolytics in patients with threatened preterm labor [1].
It is well known fact that women with history of preterm birth are at increased risk of preterm birth in subsequent pregnancies. However, a recent study showed that women with threatened preterm labor delivering at term in first pregnancy were at increased risk of preterm birth in next pregnancy with Odds ratio of 2.21 [16]. Therefore, history of TPTL should be elicited in subsequent pregnancies so that proper surveillance can be done.

A latest study in Spain had cited that children of patients who presented with threatened preterm labor in their pregnancy but delivered at term had increased risk of mild neurodevelopmental delay when compared to uncomplicated pregnancy children [17]. Another study conducted in Greece showed that $24.3 \%$ prevalence of antenatal depression (based on Edinburgh Postnatal depression scale) in women admitted for threatened preterm labor [18]. This imposes the importance of appropriate diagnosis in these women so that they do not suffer unnecessary stress due to hospitalization and improper diagnosis.

Preterm labor is the most common clinical scenario encountered worldwide. Even though, in the last two decades, there has been enormous development in the evolution of diagnostic tests to predict preterm labor, still threatened preterm labor remains one of the most common causes for antenatal hospitalizations. The researches and observational studies had showed that the use of these tests predicted preterm labor precisely with cost effectiveness but the meta analysis proved a contrary result. Therefore, it is essential that large multicenter trials must be conducted on these tests in order to confirm if the use of these tests convincingly reduce hospital expenses or not. Threatened preterm labor has always remained a serious concern in small, peripheral centers where decision making would determine the short term and long term neonatal outcomes. Our knowledge on threatened preterm labor is just similar to the tip of the iceberg and should be expedited in detail in the upcoming years.

\section{REFERENCES}

1. ACOG. Practice Bulletin No. 171: Management of Preterm Labor. Obstet Gynecol. 2016;128(4):155-164.

2. Songthamwat $\mathrm{S}, \mathrm{Na} \mathrm{Nan} \mathrm{C}$, Songthamwat M. Effective of nifedipine in threatened preterm labor: A randomized trial. Int J of Women's Health. 2018;10:317-323.

3. Chawanpaiboon S, Sutantawibul A, Pimol K, Sirisomboon R, Worapitaksanond S. Preliminary study: Comparison of the efficacy of progesterone and nifedipine in inhibiting threatened preterm labour in Siriraj Hospital. Thai J Obstet Gynaecol. 2009;17(1):23-29.

4. Ho N, Liu C, Nguyen A, Lehner C, Amoako A, Sekar R. Prediction of time of delivery using cervical length measurement in women with threatened preterm labor. J Matern Fetal Neonatal Med. 2019;1:1-6.

5. Berghella V, Saccone G. Cervical assessment by ultrasound for preventing preterm delivery. Cochrane Database Syst Rev. 2019;9:CD007235.

6. Winden VTMS, Bruijn MMC, Oudijk MA, Baaren GJV, Kaam AHLC, Mol BWJ, et al. Fibronectin test in threatened preterm labour: cost-saving but not yet widely 
implemented in the Netherlands. Ned Tijdschr Geneeskd. 2019;162:D2134.

7. Warwick G, Andrew B, Marianne K, Gemma M, Roger S. The effect of fetal fibronectin testing on admissions to a tertiary maternal-fetal medicine unit and cost savings. Am J Obstet Gynecol. 2000;182(2):439-442.

8. Berghella $\mathrm{V}$, Saccone $\mathrm{G}$. Fetal fibronectin testing for prevention of preterm birth in singleton pregnancies with threatened preterm labor: a systematic review and metaanalysis of randomized controlled trials. Am J Obstet Gynecol. 2016;215(4):431-438.

9. Baaren GJV, Vis JY, Wilms FF, Oudijk MA, Kwee A, Porath MM, et al. Cost-effectiveness of diagnostic testing strategies including cervical-length measurement and fibronectin testing in women with symptoms of preterm labor. Ultrasound Obstet Gynecol. 2018;51(5):596-603

10. Berghella V, Saccone G. Fetal fibronectin testing for reducing the risk of preterm birth. Cochrane Database Syst Rev. 2019; 7:CD006843.

11. Meenoo S, Tripathi R, Tyagi S, Ramji S, Shah S, Mala YM. Triaging hospitalization in threatened preterm labor patients using a biochemical marker and transvaginal ultrasound: A pilot implementation study in a tertiary center of North India. J Preg Child Health. 2019;6(1):400.

12. Radan AP, Polowy AJ, Heverhagen A, Simillion C, Baumann M, Raio L, et al. Cervico-vaginal placental a-macroglobulin-1 combined with cervical length for the prediction of preterm birth in women with threatened preterm labor. Acta Obstet Gynecol Scand. 2019
13. Davutoglu AE, Firat AA, Ozel A, Uzun I, Ozer N, Madazli R, et al. The utility of maternal serum endocan level to predict preterm delivery within seven days in patients with threatened preterm labor. J Matern Fetal Neonatal Med. 2019;21:1-6.

14. Ashraf B. Efficacy and safety of oral nifedipine with or without vaginal progesterone in the management of threatened preterm labor. Int J Reprod Biomed (Yazd). 2019;17(9):629-636.

15. Jaju PB. Effectiveness and Safety of Isoxsuprine Hydrochloride as Tocolytic Agent in Arresting Active/Threatened Preterm Labor and Its Role in Maintenance Tocolysis -A Prospective, Open-Label Study. Am J Perinatol. 2019.

16. Cho GJ, Choi SJ, Lee KM, Han SW, Kim HY, Ahn KH, et al. Women with threatened preterm labour followed by term delivery have an increased risk of spontaneous preterm birth in subsequent pregnancies: A population based cohort study. BJOG. 2019;126(7):901-905.

17. Paules C, Pueyo V, Martí E, Vilchez SD, Burd I, Calvo P, et al. Threatened preterm labor is a risk factor for impaired cognitive development in early childhood. Am J Obstet Gynecol. 2017;216(2):157.e1-157.e7.

18. Dagklis T, Tsakiridis I, Chouliara F, Mamopoulos A, Rousso D, Athanasiadis A, et al. Antenatal depression among women hospitalized due to threatened preterm labor in a high-risk pregnancy unit in Greece. J Matern Fetal Neonatal Med. 2018;31(7):919-925. 